\title{
EFFECTS OF CRYSTALLIZATION AND PLASTIC FLOW ON THE THERMOLUMINESCENCE OF ICE
}

\author{
By L. B. Ronca and E. J. Zeller \\ (Department of Geology, The University of Kansas, Lawrence, Kansas, U.S.A.)
}

\begin{abstract}
Glow-curves of ice, made in the laboratory, have a distribution of peak-height ratios, with the maximum at approximately $0 \cdot 75$. The distribution was probably caused by varying conditions of crystallization, impossible to control with the present equipment. Glow-curves of ice which has been made to flow have a distribution of peak ratios with the maximum at approximately $\mathrm{I} \cdot 75$.

It is concluded that dislocations in the crystal lattice effect the peak ratio. Dislocations are produced during crystallization by internal stresses, and to a greater extent, by external forces during the flow.
\end{abstract}

RÉsumé. Les courbes de thermoluminescence de la glace produite en laboratoire ont une distribution des rapports de la hauteur des pics avec un maximum d'environ 0,75 . Des conditions variables de cristallisation, impossibles à contrôler avec les moyens actuels, causent probablement cette distribution. Les courbes de thermoluminescence émises par de la glace ayant subi un écoulement, ont une distribution des rapports de la hauteur des pics avec un maximum d'environ 1,75 .

On en conclut que les dislocations dans le réseau cristallin influent sur le rapport des pics. Les dislocations sont produites pendant la cristallisation par des forces internes et de façon plus marquée par des forces externes durant l'écoulement.

Zusammenfassung. Das Maximum der Verteilung der Kurvenscheitelpunktsverhältnisse von GlühKurven die an Eis hergestellt im Labor beobachtet wurden, liegt bei etwa 0,75 . Diese Verteilung wurde vermutlich durch unterschiedliche Verhältnisse beider Kristallisierung verursacht, die man mit den derzeit vorhandenen Geräten nicht kontrollieren kann. Glüh-Kurven von Eis, das zum Fliessen gebracht worden war, weisen eine Verteilung der Kurvenscheitelpunktsverhältnisse mit einem Maximum bei etwa 1,75 auf.

Daraus folgt, dass Versetzungen im Kristallgitter das Kurvenscheitelpunktsverhältnis beeinflussen. Sie entstehen während des Kristallisierungsvorganges einmal durch innere Spannungen, in grösserem Ausmass aber durch äussere Kräfte während des Fliessvorganges.

\section{INTRODUCTION}

Glow-curves of ice samples irradiated by ultraviolet light at liquid-nitrogen temperature show two peaks, a narrow one at approximately $-190^{\circ} \mathrm{C}$. and a broader one at about $-140^{\circ} \mathrm{C}$. (Zeller and Ronca, I963). A ratio of the height of the broad peak to the height of the sharp peak was found to be directly related to the previous pressure history of the ice. A two-minute exposure to ultraviolet radiation, followed by two minutes of standing time at liquid-nitrogen temperature before running of the glow-curve, resulted in a ratio that ranged from 0.32 for fresh snow to $3 \cdot$ I 2 for glacial ice containing flow structures. A set of laboratory experiments was initiated to obtain more information on the thermoluminescence of ice; the results of these experiments are presented in this paper.

\section{Effects of Dosage of Radiation and Standing Time}

The importance of the amount of radiation and the length of time between the end of the irradiation and the running of the glow-curve was observed in the early stages of this research. Both glow-curve peaks are a function of two variables: dosage of irradiation and length of standing time. The effects of the variables were studied by holding one variable constant and varying the other. First, the standing time was held constant at two minutes, and the irradiation dosage was increased. The glow-curve peaks produced are proportional to the amount of radiation, until a maximum value is reached. Successive increments of radiation do not increase the amount of thermoluminescence, thus indicating that a saturation value is essentially reached. However, soon after saturation is reached, the glow-curve begins to lose its sharpness and the peaks become broader and less defined. It was found that a two-minute irradiation gave the best results. The length of the exposure is probably related to the intensity of the ultraviolet source and could be expected to be dependent upon the apparatus used. For the specific source used in these experiments, a two-minute irradiation was adequate to attain the saturation value, but the peaks are still sharp and well defined. 
Later, the effects of different amounts of time between the end of the irradiation and the running of the glow-curve were studied by keeping the amount of ultraviolet radiation constant at two minutes and varying the standing time in liquid nitrogen. In general, both peaks decay rapidly in the first two minutes, after which the decay is very small. Short standing time was found to produce highly erratic results and two-minute standing time gave the most constant curves. This phenomenon can be best explained by assuming that ultraviolet radiation fills the traps that normally should be empty at liquid-nitrogen temperature. If the sample is allowed to stand, decay proceeds even at liquid-nitrogen temperature until equilibrium is reached. Short standing times are thought to give erratic results partly through the effects of the phosphorescence that may develop in the sample.

\section{Effects of Crystallization and Flow}

- Glow-curves obtained from artificially made ice show a wide variation in their thermoluminescence characteristics because it is difficult to duplicate the amount of lattice imperfections in individual samples. To maintain standardization, care was taken to avoid fracturing of the ice during solidification. A temperature of approximately $-10^{\circ} \mathrm{C}$. was chosen. The water was put into containers of aluminum foil to minimize the development of lateral pressure during freezing. Unfortunately, the refrigerator thermostat allowed a variation in temperature in the freezing chamber exceeding $5^{\circ} \mathrm{C}$.

The frequency distribution of the peak ratios obtained from 69 glow-curves is shown in Figure I. It seems likely that better temperature control during crystallization and a standardization of the dissolved-gas content would narrow the peak. It is hoped that better equipment will permit the determination of the effects of each of the above factors. The distribution was probably caused by different rates of crystallization resulting from differences in the temperature of the chamber in which the freezing took place. During the crystallization, pressures are probably developed inside the solid. Differing quantities of dissolved ions and gases in the water are also thought to effect the glow-curve characteristics. Only distilled water was used, and work is planned using solutions of varying concentrations of certain salts. No systematic difference was noticed between ice frozen in bulk and in layers. Atmospheric gases were not

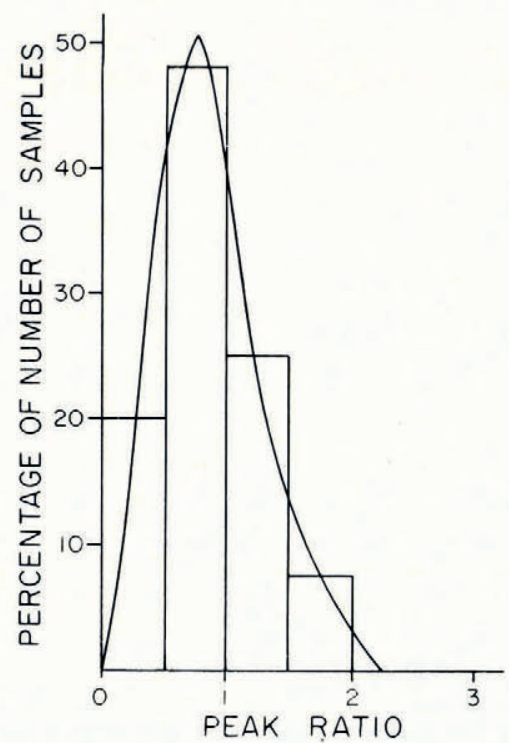

Fig. I. Frequency distribution of peak ratios for unpressed artificial ice 
controlled, and it is known that oxygen has a strong effect on the thermoluminescence of some solids (Curie, I963, p. 64). Figure $\mathrm{I}$ shows that a value between 0.5 and $\mathrm{I} \cdot 0$ is the most probable peak ratio for unpressed ice.

The effects of pressure were measured by squeezing the ice from a cylinder with a height of $3.6 \mathrm{~cm}$. and a diameter of $4.0 \mathrm{~cm}$. to a new cylindrical shape $3.0 \mathrm{~cm}$. in height and approximately $4.4 \mathrm{~cm}$. in diameter. This was done by placing the unpressed cylinder in a plastic cylindrical mold having an inside diameter of $4.4 \mathrm{~cm}$. A diagram of the mold is shown in Figure 2. A piston squeezed the ice until the diameter of the ice cylinder was equal to the inside diameter of the plastic cylinder. The force was obtained by a second-class lever with a weight on the extremity.

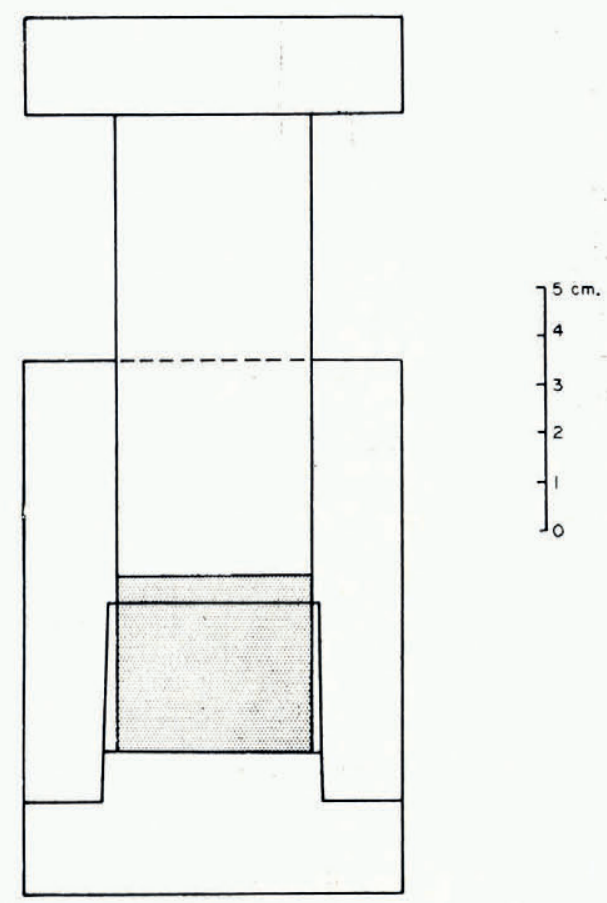

Fig. 2. Diagram of the mold used to produce the plastic flow

To avoid megascopic cracking in the ice, the amount of weight on the extremity of the lever was gradually increased through a period of about one week. At the temperature used, the complete flowage took place in about ten days. Because of the poor temperature control in the refrigerator, the plasticity of the ice was not constant. The pressure when all the weights were on the extremity of the lever, was about $26 \mathrm{~kg} . / \mathrm{cm} .^{2}$. Figure 3 , based on a total of $5^{0}$ glow-curves, shows the frequency distribution of the peak ratios obtained from the squeezed ice samples. In this case the distribution has a peak between $\mathrm{I} \cdot 5$ and $2 \cdot 0$. The distribution is much narrower than in the case of unpressed ice, thus indicating that the effects of squeezing tend to obliterate effects produced during crystallization. It is impractical with the present equipment to obtain sufficient data to plot a graph of the peak ratio versus the amount of flowage. Because the results obtained require a statistical treatment for interpretation, a large number of sample pressings must be made. The time required for each pressing is such that new equipment must be constructed before the research can be completed in a reasonable length of time. 


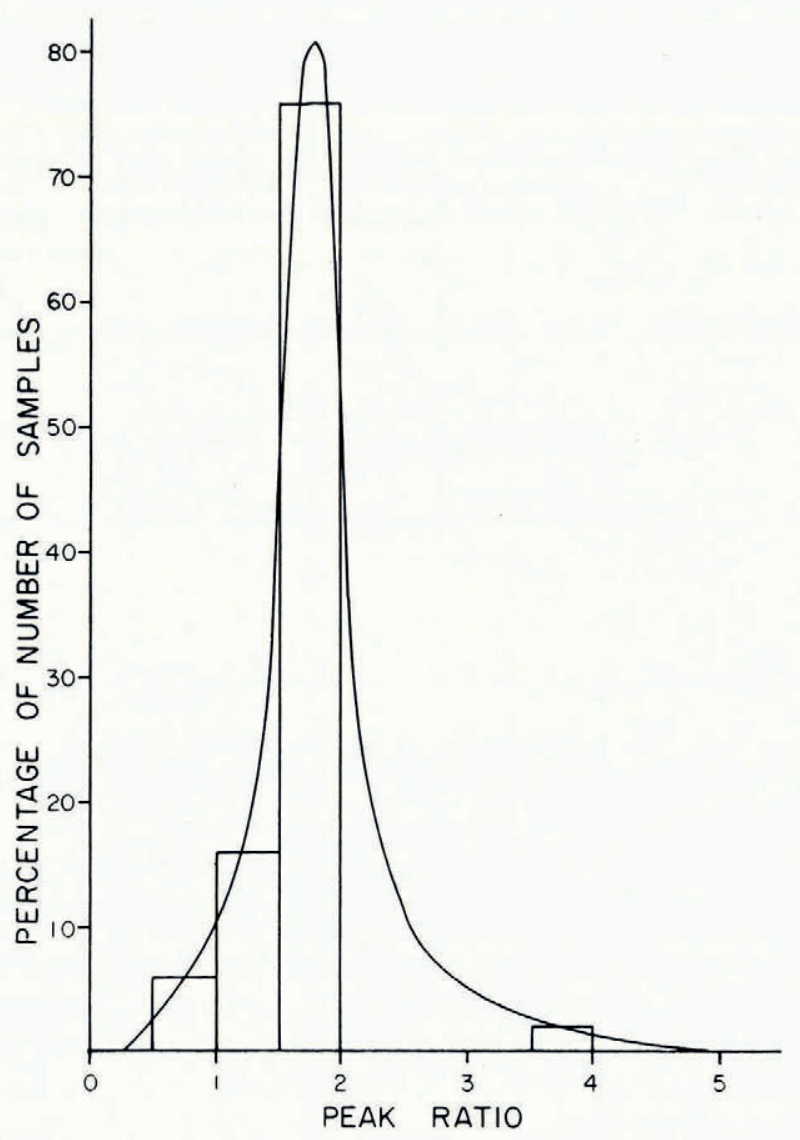

Fig. 3. Frequency distribution of peak ratios for ice subjected to plastic flow

\section{Discussion}

Although no quantitative conclusions can be reached at this stage of research, it seems apparent that the glow-curve peak ratio is an index of stress on the ice. The fact that the peak ratio of glow-curves obtained from unpressed ice may show a peak ratio of the same value as that for pressed ice is explained by postulating stresses that develop during the process of freezing. In the essentially uncontrolled freezing of the experiments, different rates of solidification are to be expected. The randomly oriented crystals, which seem to grow more rapidly in the basal plane (Pounder, I963), are likely to produce local stresses.

Gold (1963) has shown that the first response to an applied stress is a deformation that apparently involves the movement of dislocations. Dislocations are known to be able to trap electrons and therefore affect thermoluminescence (Angino, I959). When pressure is applied to ice, the number of dislocations produced will be dependent on the orientation of the ice crystals, as ice crystals have only one effective slip plane (Steinemann, I 954). As ice is deformed the inability of some grains to conform to the deformation must result in local stresses between grains. These stresses will ultimately produce further dislocations.

Thermoluminescence of ice is a sensitive method for determining the history of ice. It is hoped that it will become a tool for the theoretical glaciologist as well as the ice engineer. As a practical example, attention is called to the fact that thermal stresses can have a significant effect on the bearing capacity of ice. Thermally stressed ice will, in many cases, crack when 
drilled or walked upon. Gold ( 1963 ) believed that many of the ice failures that have occurred in the normal hauling operations of Canadian pulp and paper companies across frozen lakes are the results of stresses or associated cracks formed in the ice cover by changing temperature. Perhaps glow-curves of the ice under winter roadways would be diagnostic.

\section{ACKNoWledgements}

The writers thank M. D. Turner, Mrs. L. M. Turner and S. M. Jamkhindikar for their help in the laboratory experiments and in the writing of the paper. Economic assistance from the National Science Foundation of the United States, Contract Number Gi 3503, is gratefully acknowledged.

MS. received 5 May 1964

\section{REFERENCES}

Angino, E. E. 1959. Some effects of pressure on the thermoluminescence of limestone. Fournal of Geophysical Research, Vol. 64, No. Io, p. $1638-40$.

Curie, D. I963. Luminescence in crystals. Translated by G. F. F. Garlick [and] incorporating later revisions by the author and translator. London, Methuen and Co., Ltd.; New York, John Wiley and Sons, Inc.

Gold, L. W. 1963. Deformation mechanisms in ice. (In Kingery, W. D., ed. Ice and snow; properties, processes, and applications: proceedings of a conference held at the Massachusetts Institute of Technology, February 12-16, 1962. Cambridge, Mass., The M.I.T. Press, p. 8-27.)

Pounder, E. R. 1963. Crystal growth rates as a function of orientation. (In Kingery, W. D., ed. Ice and snow; properties, processes, and applications: proceedings of a conference held at the Massachusetts Institute of Technology, February $12-16$, I962. Cambridge, Mass., The M.I.T. Press, p. 226-31.)

Steinemann, S. 1954. Results of preliminary experiments on the plasticity of ice crystals. Fournal of Glaciology, Vol. 2, No. I6, p. 404-13.

Zeller, E. J., and Ronca, L. B. I963. Thermoluminescence techniques in determination of the stress and crystallization history of ice. fournal of Glaciology, Vol. 4, No. 34, p. 453-60. 